malaria. Thus, derivatives of GA or other traditional medicines might be used in the future for treating human diseases caused by latent virus infections.

Address correspondence to: Jeffrey I. Cohen, Medical Virology Section, Laboratory of Clinical Infectious Diseases, Building 10, Room 11N228, NIH, 10 Center Drive, MSC 1888, Bethesda, Maryland 20892, USA. Phone: (301) 496-5265; Fax: (301) 496-7383; E-mail: jcohen@niaid.nih.gov.

1. Ploeger, B., et al. 2001. The pharmacokinetics of glyc yrrhizic acid evaluated by physiologically based pharmacokinetic modeling. Drug Metab. Rev. 33:125-147.

2. Curreli, F., Friedman-Kien, A.E., and Flore, O. 2005 Glycyrrhizic acid alters Kaposi sarcoma-associated herpesvirus latency, triggering p53-mediated apoptosis in transformed B lymphocytes. J. Clin. Invest. 115:642-652. doi:10.1172/JCI200523334.

3. Katano, H., Sato, Y., Kurata, T., Mori, S, and Sata, T. 2000. Expression and localization of human herpesvirus 8-encoded proteins in primary effusion lymphoma, Kaposi's sarcoma, and multicentric Castleman's disease. Virology. 269:335-344.

4. Parravicini, C., et al. 2000. Differential viral protein expression in Kaposi's sarcoma-associated herpesvirus-infected diseases: Kaposi's sarcoma, primary effusion lymphoma, and multicentric Castleman's disease. Am. J. Pathol. 156:743-749.

5. Moore, P, and Chang, Y. 2001. Kaposi's sarcomaassociated herpesvirus. In Fields virology. D.M. Knipe and P.M. Howley, editors. Lippincott Williams \& Wilkins. Philadelphia, Pennsylvania, USA. 2803-2833.

6. Guasparri, I., Keller, S.A., and Cesarman, E. 2004 KSHV vFLIP is essential for the survival of infected lymphoma cells. J. Exp. Med. 199:993-1003.

7. Matta, H., and Chaudhary, P.M. 2004. Activation of alternative NF-kappa B pathway by human herpes virus 8-encoded Fas-associated death domain-like IL-1 beta-converting enzyme inhibitory protein (vFLIP). Proc. Natl. Acad. Sci. U. S. A. 101:9399-9404.

8. Keller, S.A., Schattner, E.J., and Cesarman, E. 2000 Inhibition of NF-кB induces apoptosis of KSHVinfected primary effusion lymphoma cells. Blood. 96:2537-2542.

9. Aoki, Y., Feldman, G.M., and Tosato, G. 2003. Inhibition of STAT3 signaling induces apoptosis and decreases surviving expression in primary effusion lymphoma. Blood. 101:1535-1542.

10. Drexler, H.G., Meyer, C., Gaidano, G., and Carbone, A. 1999. Constitutive cytokine production by primary effusion (body cavity-based) lymphomaderived cell lines. Lenkemia. 13:634-640.

11. Foussat, A., et al. 1999. Human interleukin-6 is in vivo an autocrine growth factor for human herpesvirus-8-infected malignant B lymphocytes. Eur. Cytokine Netw. 10:501-508.

12. Jones, K.D., et al. 1999. Involvement of interleukin10 (IL-10) and viral IL-6 in the spontaneous growth of Kaposi's sarcoma herpesvirus-associated infected primary effusion lymphoma cells.
Blood. 94:2871-2879.

13. Aoki, Y., and Tosato, G. 1999. Role of vascular endothelial growth factor/vascular permeability factor in the pathogenesis of Kaposi's sarcomaassociated herpesvirus-infected primary effusion lymphomas. Blood. 94:4247-4254.

14. Chodosh, J., et al. 1998. Eradication of latent Epstein-Barr virus by hydroxyurea alters the growth-transformed cell phenotype. J. Infect. Dis. 177:1194-1201.

15. Slobod, K.S., et al. 2000. Epstein-Barr virus-targeted therapy for AIDS-related primary lymphoma of the central nervous system. Lancet. 356:1493-1494.

16. Mentzer, S.J., Perrine, S.P., and Faller, D.V. 2001. Epstein--Barr virus post-transplant lymphoproliferative disease and virus-specific therapy: pharmacological re-activation of viral target genes with arginine butyrate. Transpl. Infect. Dis. 3:177-185.

17. Feng, W.H., Hong, G., Delecluse, H.J., and Kenney, S.C. 2004. Lytic induction therapy for EpsteinBarr virus-positive B-cell lymphomas. J. Virol. 78:1893-1902.

18. Gottschalk, S., Rooney, C.M., and Heslop, H.E. 2005. Post-transplant lymphoproliferative disorders. Ann. Rev. Med. 56:29-44.

19. Bollard, C.M., et al. 2004. Cytotoxic T lymphocyte therapy for Epstein-Barr Virus+ Hodgkin's disease. J. Exp. Med. 200:1623-1633.

20. Van Rossum, T.G.J., Vulto, A.G., Hop, W.C.J., and Schalm, S.W. 1999. Pharmacokinetics of intravenous glycyrrhizin after single and multiple doses in patients with chronic hepatitis $\mathrm{C}$ infection. Clin. Ther. 21:2080-2090.

\title{
Unlocking the DEAD-box: a key to cryptococcal virulence?
}

\author{
Lena J. Heung' and Maurizio Del Poeta ${ }^{1,2}$
}

${ }^{1}$ Departments of Biochemistry and Molecular Biology, and 2Microbiology and Immunology, Medical University of South Carolina, Charleston, South Carolina, USA.

\begin{abstract}
The DEAD-box RNA helicases are enzymes involved in many critical aspects of RNA metabolism within both eukaryotic and prokaryotic organisms. Several studies have shown that these proteins may have important functions in mediating microbial pathogenesis. A new study in this issue of the JCI identifies the first DEAD-box RNA helicase in the pathogenic fungus Cryptococcus neoformans and proposes novel roles for this family of proteins in the development and progression of cryptococcosis (see the related article beginning on page 632 ).
\end{abstract}

Cryptococcosis is a chronic human disease caused by the ubiquitous environmental fungus Cryptococcus neoformans. The disease occurs after inhalation of yeast cells or basidiospores into the alveo-

Nonstandard abbreviations used: Not, negative on TATA-less; RNAi, RNA interference; SF, superfamily; Vad1, virulence-associated DEAD-box RNA helicaseencoding protein.

Conflict of interest: The authors have declared that no conflict of interest exists.

Citation for this article: J. Clin. Invest. 115:593-595 (2005). doi:10.1172/JCI200524508. lar spaces and eventually progresses with the dissemination of $C$. neoformans to the central nervous system, causing meningoencephalitis (1). The majority of cryptococcosis cases have been reported in immunocompromised patients, such as subjects with AIDS or those undergoing transplantation, but certain varieties of C. neoformans do affect immunocompetent hosts (1). Current therapies cannot completely eradicate the chronic infection, which necessitates life-long treatment. Therefore, studies addressing the under- standing of pathophysiological processes leading to the development of the disease are particularly important for the discovery of new therapeutic strategies. C. neoformans is a facultative intracellular pathogen with several well-established virulence factors, including growth at $37^{\circ} \mathrm{C}$ (temperature of the mammalian host), a large antiphagocytic polysaccharide capsule, and the laccase enzyme, which can produce melanin pigments from host-derived substrates. With the goal of identifying novel targets for drug development, current Cryptococcus research is focused on the signaling networks that regulate these virulence factors. A few virulence-related pathways have been identified in C. neoformans, including the $\mathrm{G} \alpha$ protein-cAMP-PKA and Ipc1-Pkc1 pathways $(2,3)$. In this issue of the JCI, Panepinto et al. (4) describe a new class of proteins and a novel signaling net- 


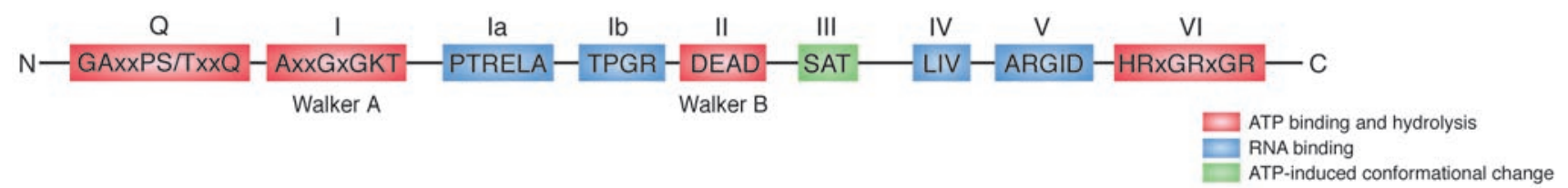

Figure 1

The 9 conserved motifs of the DEAD-box RNA helicase family and their putative functions (6). Motifs I and II, also known as the Walker A and $\mathrm{B}$ motifs, bind nucleotide triphosphates; the DEAD-box helicases are named after the amino acid sequence of motif II. Motifs $\mathrm{Q}$ and $\mathrm{VI}$ are also involved in binding ATP for hydrolysis. Motifs la, Ib, IV, and V are proposed to bind RNA. Motif III may induce conformational changes required for helicase activity upon ATP binding.

work in C. neoformans by identifying the first putative DEAD-box RNA helicase, named virulence-associated DEAD-box RNA helicase-encoding protein (Vad1). Here we discuss the DEAD-box helicases, their roles in pathogenesis, and the significance of this discovery in an important fungal pathogen.

\section{What is a DEAD-box RNA helicase?}

Helicase proteins are classically defined as ATP-dependent enzymes that separate DNA and/or RNA duplexes, and they are divided into superfamilies (SFs) I-III based on sequence similarity, without distinguishing between DNA and RNA helicases (5). Many RNA helicases have been shown to have ATPase activity in the presence of RNA, but not all have demonstrated actual unwinding activity, probably due to a lack of specific substrates and/or cofactors in an in vitro system (6). RNA helicases may also exhibit other activities, such as disrupting RNA-protein complexes (6). Thus, RNA helicase function is presently not fully defined.

Members of the helicase families share several conserved motifs, including the Walker A and B motifs, which are involved in the binding of nucleoside triphosphates. The DExD/H-box RNA helicases (named for the consensus amino acid sequence of the Walker B motif) belong to the second superfamily of helicases (SF-II) and are divided into 3 families: Ski 2, DEAH-box, and DEAD-box. The DEADbox proteins share a total of 9 conserved domains, inclusive of the Walker motifs (Figure 1), and have been implicated in multiple cellular processes, including gene transcription, RNA splicing, ribosome biogenesis, RNA transport, translation initiation, mitochondrial gene expression, and mRNA degradation (6).

DEAD-box proteins are found in a variety of organisms, both eukaryotes and prokaryotes, but are absent in some organisms, including bacteria such as
Chlamydia and Borrelia and archaea such as Pyrococcus and Halobacterium (6). The number of DEAD-box helicases also varies: Saccharomyces cerevisiae has 25 , and humans have 36 putative DEAD-box helicases, whereas other organisms, such as the archaean Methanococcus, have only 1 (6-8).

\section{Pathogenesis and DEAD-box proteins}

Several studies suggest that DEAD-box proteins are crucial to signaling pathways that mediate host-pathogen interactions. For example, several mammalian DEADbox helicases have putative roles in replication and nuclear export of HIV-1 RNA (9, 10). Paramyxovirus proteins can bind to the mammalian DEAD-box helicase melanoma differentiation-associated gene 5 to block its activation of the IFN- $\beta$ promoter, thus preventing the antiviral IFN response (11). Proteins from other viruses, such as hepatitis $C$ virus and human papillomavirus, have also been shown to bind DEAD-box proteins, although the significance of these interactions to virulence is unclear (12-16). Pathogen-derived helicases may also play a role in pathogenesis. In the parasite Trypanosoma cruzi, the putative DEADbox helicase HelTc is upregulated in trypomastigotes, the infective form of the organism (17). Interestingly, the bacterial RNA helicases have been studied mainly for mechanistic purposes rather than in the context of host-pathogen interaction. However, there are some reports that suggest bacterial DEAD-box proteins are also involved in pathogenesis. For instance, Helicobacter pylori deaD may play a role in regulating urease activity (18), and in the anaerobic bacterium Clostridium perfringens, a DEAD-box RNA helicase may be involved in the adaptive response to oxidative stress (19). The model system for study of fungal DEAD-box proteins has been the nonpathogenic yeast $S$. cerevisiae. DEAD-box helicases have been identi- fied in pathogenic fungi, such as Chr1 in Candida albicans (20) and HelA in Aspergillus nidulans (21), but unlike Vad1 in C. neoformans, these proteins do not yet have defined roles in virulence.

\section{Cryptococcal DEAD-box proteins: a new paradigm for study}

Clearly, the role of pathogen-derived DEAD-box helicases in virulence pathways needs further exploration. Panepinto and coworkers identified the C. neoformans DEAD-box helicase Vad1 through a random mutagenesis screen for defects in the virulence factor laccase (4). The C. neoformans strain $\Delta$ vad 1 (in which the VAD1 gene is disrupted) was analyzed by differential display, and 4 transcripts (other than LAC1-encoding laccase) were found to be modulated. The roles of these genes in the phenotype exhibited by the $\Delta \operatorname{vad} 1$ strain were investigated by the examination of deletion mutants or gene suppression by RNA interference (RNAi). This study of Vad1 and the genes it modulates introduces what we believe to be the first known putative roles for the DEAD-box helicases in fungal pathogenesis. First, Vad1 may have a role in the ability of $C$. neoformans to sense the host environment upon initial infection. By homology, Vad1 belongs to the $\mathrm{RCK} / \mathrm{p} 54$ subfamily of DEAD-box proteins. The proteins of this subfamily are known to interact with the CCR-negative on TATA-less (Ccr4-Not) complex, which has multiple roles in regulating gene expression and may work with DEAD-box helicases to facilitate RNA degradation (22). One of the transcripts regulated by Vad1 was shown to be NOT1, a component of the Ccr4-Not complex. Interestingly, it has been proposed that Ccr4-Not may be able to sense glucose depletion and other environmental stresses that could be found within a host system (22). Therefore, the association between Vad1 and Not 1 could play an important role in coordinating the ability of C. neoformans 
to detect the host environment. Second, Vad1 may initiate signaling pathways that will enable the survival of a fungal cell within that environment. The other transcripts modulated by Vad1 include PCK1, which encodes phosphoenolpyruvate carboxykinase; TUF1, which encodes an elongation factor for mitochondrial protein translation; and MPF3, which may encode a mannoprotein. These proteins have roles in gluconeogenesis, mitochondrial function, and cell wall integrity, respectively, processes that are crucial to survival in the host environment. Finally, in response to the host environment, Vad1 may regulate expression of specific antihost virulence factors. Vad1 was originally identified because its absence causes a decrease in the transcription and activity of the virulence factor laccase. This suggests that Vad1 not only modifies normal metabolic pathways upon infection but also actively helps to express a virulence factor that will promote the pathogenesis of C. neoformans.

Is Vad1 a "master regulator" of this virulence network as Panepinto et al. (4) propose? There are many interesting questions still to be answered, which will be aided by the biochemical characterization of Vad1. Does it truly function as a helicase? As with its DEAD-box relatives, does it interact with the Ccr4-Not complex? How does Vad1 specifically regulate only the LAC1, NOT1, PCK1, TUF1, and MPF3 transcripts? Does it possess substrate specificity? Are there more DEAD-box homologs to be found in C. neoformans, and could they also play important roles in regulating other virulence cascades?

Although investigations into the role of DEAD-box RNA helicases in fungal pathogenesis are relatively new, they have already shown us the value of transcriptome analysis to identify novel cellular connections and have shed new light on how C. neoformans regulates its pathogenesis. Results from future studies of DEAD-box helicases may be the key to effectively clearing cryptococcal infections and improving the quality of life for many immunocompromised patients.

\section{Acknowledgments}

We thank Yusuf A. Hannun and Jennifer G. Schnellmann for editorial assistance. M. Del Poeta is supported by grants from the NIH (AI56168 and RR17677 Project 2) and from Burroughs Wellcome Fund. L. Heung is supported by NIH training grant GM08716. M. Del Poeta is a Burroughs Wellcome New Investigator in Pathogenesis of Infectious Diseases.

Address correspondence to: Maurizio Del Poeta, Department of Biochemistry, Medical University of South Carolina, Charleston, South Carolina 29425, USA. Phone: (843) 792-8381; Fax: (843) 792-8565; E-mail: delpoeta@musc.edu.

1. Casadevall, A., and Perfect, J.R. 1998. Cryptoccus neoformans. ASM Press. Washington, D.C., USA. 541 pp. 2. D'Souza, C.A., et al. 2001. Cyclic AMP-dependent protein kinase controls virulence of the fungal pathogen Cryptococcus neoformans. Mol. Cell. Biol. 21:3179-3191.

3. Heung, L.J., Luberto, C., Plowden, A., Hannun, Y.A., and Del Poeta, M. 2004. The sphingolipid pathway regulates $\mathrm{Pkc1}$ through the formation of diacylglycerol in Cryptococcus neoformans. J. Biol. Chem. 279:21144-21153.

4. Panepinto, J., et al. 2004. The DEAD-box RNA helicase Vad1 regulates multiple virulence-associated genes in Cryptococcus neoformans. J. Clin. Invest. 115:632-641. doi:10.1172/JCI200523048.

5. Gorbalenya, A.E., and Koonin, E.V. 1993. Helicases: amino acid sequence comparisons and structure-function relationships. Curr. Opin. Struct. Biol. 3:419-429.

6. Rocak, S., and Linder, P. 2004. DEAD-box proteins: the driving forces behind RNA metabolism. Nat. Rev. Mol. Cell. Biol. 5:232-241.

7. de la Cruz, J., Kressler, D., and Linder, P. 1999. Unwinding RNA in Saccharomyces cerevisiae: DEAD-box proteins and related families. Trends Biochem. Sci. 24:192-198.
8. Abdelhaleem, M., Maltais, L., and Wain, H. 2003. The human DDX and DHX gene families of putative RNA helicases. Genomics. 81:618-622.

9. Yedavalli, V.S., Neuveut, C., Chi, Y.H., Kleiman, L., and Jeang, K.T. 2004. Requirement of DDX3 DEAD box RNA helicase for HIV-1 Rev-RRE export function. Cell. 119:381-392.

10. Fang, J., et al. 2004. A DEAD box protein facilitates HIV-1 replication as a cellular co-factor of Rev. Virology. 330:471-480.

11. Andrejeva, J., et al. The $\mathrm{V}$ proteins of paramyxoviruses bind the IFN-inducible RNA helicase, mda-5, and inhibit its activation of the IFNbeta promoter. Proc. Natl. Acad. Sci. U. S. A. 101:17264-17269.

12. Goh, P.Y., et al. 2004. Cellular RNA helicase p68 relocalization and interaction with the hepatitis C virus (HCV) NS5B protein and the potential role of $\mathrm{p} 68$ in HCV RNA replication. J. Virol. 78:5288-5298.

13. Doorbar, J. et al. 2000. The E1E4 protein of human papillomavirus type 16 associates with a putative RNA helicase through sequences in its C terminus. J. Virol. 74:10081-10095.

14. You, L.R., et al. 1999. Hepatitis C virus core protein interacts with cellular putative RNA helicase. J. Virol. 73:2841-2853.

15. Owsianka, A.M., and Patel, A.H. 1999. Hepatitis C virus core protein interacts with a human DEAD box protein DDX3. Virology. 257:330-340.

16. Mamiya, N., and Worman, H.J. 1999. Hepatitis C virus core protein binds to a DEAD box RNA helicase. J. Biol. Chem. 274:15751-15756.

17. Diaz Anel, A.M., et al. 2000. MRNA encoding a putative RNA helicase of the DEAD-box gene family is up-regulated in trypomastigotes of Trypanosoma cruzi.J. Eukaryot. Microbiol. 47:555-560.

18. Bijlsma, J.J., Vandenbroucke-Grauls, C.M., Phadnis, S.H., and Kusters, J.G. 1999. Identification of virulence genes of Helicobacter pylori by random insertion mutagenesis. Infect. Immun. 67:2433-2440.

19. Briolat, V., and Reysset, G. 2002. Identification of the Clostridium perfringens genes involved in the adaptive response to oxidative stress. J. Bacteriol. 184:2333-2343.

20. Kim, W.I., Lee, W.B., Song, K., and Kim, J. 2000. Identification of a putative DEAD-box RNA helicase and a zinc-finger protein in Candida albicans by functional complementation of the $S$. cerevisiae rok1 mutation. Yeast. 16:401-409.

21. Ribard, C., Scazzocchio, C., and Oestreicher, N. 2001. The oxpA5 mutation of Aspergillus nidulans is an allele of adB, the gene encoding adenylosuccinate synthetase. Mol. Genet. Genomics. 266:701-710.

22. Collart, M.A. 2003. Global control of gene expression in yeast by the Ccr4-Not complex. Gene. 313:1-16. 